\title{
Steam Regeneration of Adsorbents: An Experimental and Technical Review
}

\author{
IRFAN K. SHAH ${ }^{\mathrm{a}^{*}}$, PASCALINE PRE $^{\mathrm{b}}$ and BABU J. ALAPPAT ${ }^{\mathrm{c}}$ \\ ${ }^{a}$ Department of Environmental Sciences, Central University of Jammu, India \\ ${ }^{\mathrm{b}}$ GEPEA, UMR CNRS 6144, Ecole des Mines de Nantes, Département Systèmes \\ Energétiques et Environnement, 44307 Nantes Cedex 3, France \\ ${ }^{\mathrm{c}}$ Department of Civil Engineering, IIT Delhi, Hauz Khas, New Delhi, 110016, India \\ asirfan@yahoo.com
}

Received 1 February 2013 / Accepted 16 February 2013

\begin{abstract}
Once adsorption process is over adsorbent is to be discarded as waste. Generation of waste adsorbent is a serious environmental problem. Adsorbents can be regenerated and put to reuse in the same process line. Steam is well known in process industry and can be utilized for regeneration of spent adsorbents. Use of steam for regeneration has multiple benefits however regeneration as a whole process is less studied. This paper reviews the utilization of the steam for regeneration of adsorbents with special reference to technical and experimental aspects.
\end{abstract}

Keywords: Adsorption, Regeneration, Steam adsorbent reactivity, Steam cost

\section{Introduction}

Process of adsorption has been widely used in many industries at large scale for purification, separation and compliance purposes. The main categories of adsorbents used to adsorb long range of adsorbates with varying concentration are Activated Carbons, Polymeric adsorbents and zeolites. The fact that adsorption can be used with liquid and gas process streams with high efficiency, low cost and friendly operation has made it favourite process among industrial and compliance units. Adsorption is compulsory unit operation in water treatment in many regions. World demand for virgin activated carbon (the most used industrial adsorbent) is forecast to expand 5.2 percent per year through 2012 to 1.15 million metric tons. In another estimate activated carbon production is expected to reach 2.3 million metric tons by $2017^{1}$. Consumption of activated carbons for industrial use has now become an indicator of development and environmental management efficiency. The per capita consumption of active carbons (Figure 1) per year is $0.5 \mathrm{~kg}$ in Japan, $0.4 \mathrm{~kg}$ in the U.S., $0.2 \mathrm{~kg}$ in Europe and $0.03 \mathrm{~kg}$ in the rest of the world ${ }^{2}$. 


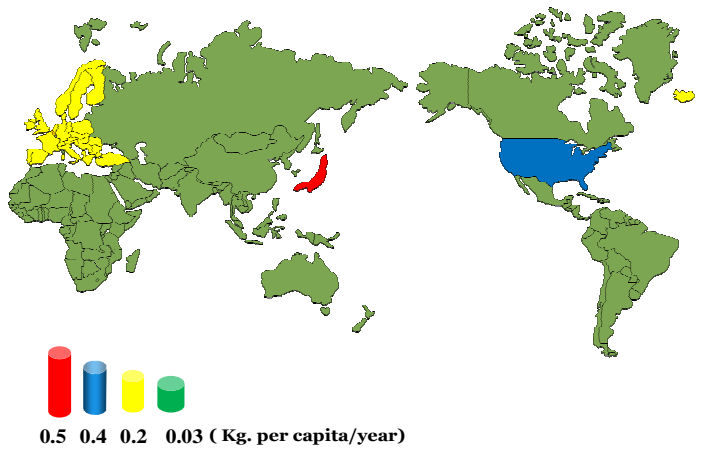

Figure 1. World adsorbent consumption ${ }^{7}$

Industries are always in search of adsorbent which has high surface area and also is specific to the target compounds. This desire has initiated enormous research in the field of adsorption. Many researchers around world are engaged in cutting edge research for developing highly specific and high performance adsorbents. The involvement of industries has led to enormous fund inflow and the end product is obviously highly adsorbing, highly specific and highly priced adsorbents developed out of patented technologies. The high cost and research and development based production technology has spurned the growth of adsorbent manufacturing industries. High adsorption capacity on the other hand has enabled industries to design huge adsorption units for long working period.

While adsorption is picking up at different industrial and commercial levels, the future of spent adsorbents is consistently becoming a concern. It is more serious in particular cases where the generation of spent adsorbents is very huge and also in cases where spent adsorbent is generated in small quantities but frequently. Adsorption being equilibrium process poses consistent danger of adsorbate being released into ambient environment on disposal or storage. Storage and dumping in many cases have been also reported to cause stinks, fires ${ }^{3}$ and explosions ${ }^{4}$.

In many case adsorbate may be a resource and need to be recovered or concentrated to earn recovery credits ${ }^{5}$. Considering all above arguments it is evident that spent adsorbent needs to be stabilized after being discarded. Because of involvement of high cost of production, stabilizing or proper disposal seems unwilling operation. Under such circumstances reuse by regeneration of adsorbent could prove double rewarding by stabilising adsorbents and recovering resource by reutilization and thereby minimizing demand for virgin adsorbents (Figure 2).

Problems associated with spent adsorbents

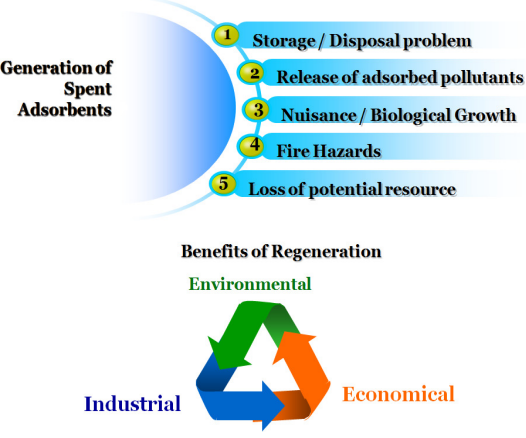

Figure 2. Problems associated with spent adsorbents and regeneration benefits ${ }^{7}$ 
Thus regeneration assumes essential importance for economical use of adsorption technique Techno economical viability of regeneration has been established and it is current research thrust area in this field. Many methods of regeneration are currently being researched which include, thermal regeneration, steam regeneration, pressure swing regeneration, vacuum regeneration, micro wave regeneration, ultrasound regeneration, chemical regeneration, oxidative regeneration, ozone regeneration, bio-regeneration. Apart from these regeneration methods combined effects of these methods have been also explored e.g. thermo chemical regeneration, electro-chemical etc.

\section{Regeneration of adsorbents}

\section{Method and types of regeneration}

Selection of method of regeneration depends upon the priority of regeneration. If adsorbate or both adsorbent and adsorbate recovery is desired physical means of regeneration are generally employed $e . g$. thermal, pressure, vacuum, microwave etc. If adsorbent recovery or adsorbent recovery with destruction of adsorbate is required then oxidative or chemical regeneration may be preferred. However this is not hard and fast rule but techno-economics generally dominates the selection of procedure for regeneration.

Regeneration have been also referred as reactivation ${ }^{6}$, Literature survey suggests that regeneration is better term for reuse of adsorbents as it includes both desorption and activation and also carves difference between desorption and regeneration. In better case the agent of desorption is also candidate for activation and hence activation step is skipped and hence regeneration can be explained as combination of desorption and activation.

In the regeneration process the following factors influence on the effectiveness of the installation performance: the degree of solution purification, the separation of a mixture into the components, adsorbent stability, the degree of recovery of adsorbed components and energy consumption. The chosen regeneration method should ensure ${ }^{8}$.

- The highest possible degree of desorption of the adsorbed compound

- The least possible erosion and the mechanical destruction of used adsorbent

- Easy access and the ecological safety of used regeneration agent

- Ease of separation of recovered or removed compounds from desorbate

- Invariable qualitative composition of desorbed components

Regeneration process can be either carried out on the site or can be carried offsite. Off site regeneration is generally carried out when the spent adsorption generation is very high. In this case spent adsorbent must be removed from the site and transported to regeneration site as hazardous material. Thermal offsite regeneration using kilns and furnaces have been reported ${ }^{9}$. Furnaces with the capacity of 5 to 60 tons/day in use have been reported ${ }^{10}$. Off site regeneration facility should be designed to regenerate huge amount of adsorbents at a time to harvest more economical benefits. However this situation becomes complicated when adsorbents laden with different target compounds from different sources arrive at regeneration facility and need to be commingled before regeneration. Onsite regeneration is considered to be expensive and thus rendering it impractical for smaller installations 9 . On site regeneration is carried out for small adsorption facilities where the adsorbate concentration is high. On site regeneration is also recommended if spent adsorbent is considered as hazardous waste ${ }^{11}$. On-site regeneration is generally not cost-effective unless the carbon exhaustion rate is over $910 \mathrm{~kg}$ per day. Carbon reactivation unit cost rises rapidly if carbon usage is less than $2272 \mathrm{~kg} /$ day $^{12}$. In U.S off-site regeneration is considered if the spent adsorbent generation rate is between 225 to $700 \mathrm{~kg}$ per day ${ }^{9}$. 
In case of thermal regeneration which is most common the temperature of regeneration decides the site for regeneration, offsite regeneration in such case ${ }^{8}$ in only preferred when regeneration temperature is between $700{ }^{\circ} \mathrm{C}-1000{ }^{\circ} \mathrm{C}$, moreover because of liability and economic concerns, many design manuals recommend that regeneration should be done offsite whenever possible, regardless of whether land and utilities are available on-site ${ }^{13}$. The adsorbent losses due to attrition have been estimated as $5-10 \%$ for in situ regeneration and $10-15 \%$ for offsite regeneration ${ }^{14}$.

However in actual practice the method adopted depends upon the cost of adsorbent and the nature of adsorbate. Amount of adsorbate adsorbed on virgin activated carbon can be determined from isotherm data however same adsorption capacity cannot be met after regeneration ${ }^{15}$. This fraction of undesorbed adsorbate has been referred as hee ${ }^{16}$. As adsorption capacity is an experimentally determined parameter and on which many design and operation condition depends. In case of in situ regeneration it becomes consistently difficult to determine the adsorption capacity of regenerated adsorbent; however empirical rules are used in trade ${ }^{15}$, Parmele et al. ${ }^{17}$, expressed the most common rule which assumes half of the solvent adsorbed during the first full loading of the adsorber remains as a residual heel after regeneration, regardless of the properties of the adsorbate and the regeneration conditions but in case of offsite regeneration it can be recalculated before redeployment of adsorbent.

In certain cases where adsorbate is a potential pollutant and its concentration is low and bed life is very long non regenerative systems may have a preference. However in such cases disposal after use is a potential hazard and thus regeneration with adsorbate destruction is important from environmental perspective.

\section{Steam regeneration}

Discovery of steam power has been turning point of human history. Steam has been used in industry since long time now. This industrial familiarity of steam thus is not new. Most industrial setups are well acknowledged with steam operation and maintenance units and hence prefer steam regeneration. Steam regeneration is widely popular and cheap ${ }^{16,18}$. Even though steam is readily available in industry it can also be generated by skid mounted boiler units which are available at relatively low cost. Steam works especially well with hydrophobic organics, such as chlorinated solvents. Hydrophobic adsorbates have an added advantage in that they can be separated from the condensed water by gravity. Steam is less useful for hydrophilic contaminants such as alcohols, aldehydes, or ketones. If steam is used for these types of contaminants, the contaminants can be separated from the condensate by distillation. However, distillation raises the Operation and Maintenance costs of the system. Hydrophobic adsorbate desorbs at temperature approaching steam distillation temperature and hydrophilic adsorbate desorbs at temperature approaching their boiling points ${ }^{19}$. After regeneration of adsorbent bed, the condensed adsorbate can be recovered by separation techniques, multiplying benefits of steam regeneration ${ }^{8}$. Steam regeneration has been repeatedly shown to be very effective and economic to regenerate active carbons and hydrophobic zeolites ${ }^{20}$.

Heating and purging properties of steam are important for regeneration and contribute equally to the regeneration of adsorbents ${ }^{21}$. The source of energy for regeneration is heat of steam and heat of adsorption of water. The heat generated by adsorption of water cannot be neglected as a driving force for regeneration of adsorbents ${ }^{22}$. During steam regeneration unlike purge gas regeneration the temperature don't drop significantly along the length of bed as the heat released due to adsorption is uniform throughout the bed ${ }^{22}$. In Steam regeneration, the high heat of condensation of steam allows the bed to be heated up rapidly, allowing for a faster desorption from the adsorbent; the desorbate is however only swept out 
of the bed when the latter is hot enough such that at least some steam remains in gaseous form and can sufficiently purge the adsorbate ${ }^{20}$. Steam also activates adsorbent and do not cause polymerization of adsorbate ${ }^{16}$. Superiority of steam over nitrogen as purging gas for low thermal desorption processes is already established ${ }^{23}$. Pelech et al. ${ }^{8}$ gave following schematics to explain regeneration of activated carbon by steam at temperature $\mathrm{T}<140{ }^{\circ} \mathrm{C}$ and $\mathrm{T}>140{ }^{\circ} \mathrm{C}$ (Figure 3 )

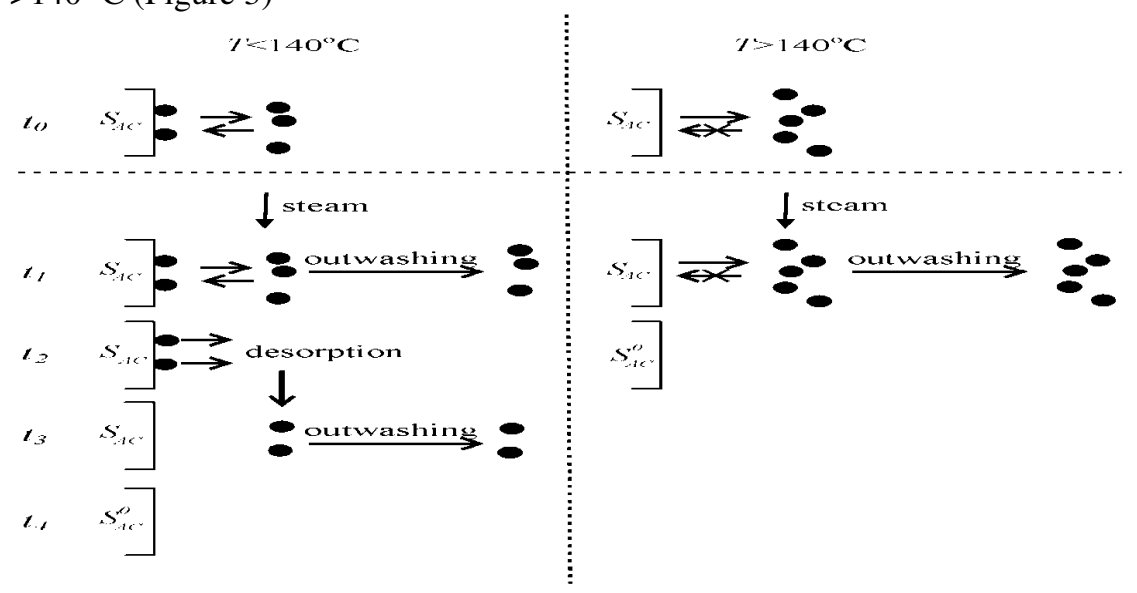

Figure 3. Schematics of steam regeneration ${ }^{8}$, Where SAC is the surface of the activated carbon, $\mathrm{S}^{0} \mathrm{AC}$ is the surface of activated carbon after regeneration, $\mathrm{t}=$ time

The above schematics explain clearly the processes taking place during steam regeneration of adsorbents and also elucidate relation between temperature and steam consumption. The scheme explains more out washing of adsorbate is required at low temperatures. Pelech et al. ${ }^{8}$ argued that, at temperatures $\mathrm{T}<140{ }^{0} \mathrm{C}$ there will be certain equilibrium between adsorbed molecules and that in the vapour phase. The flow of steam causes out washing of non adsorbed molecules. A decrease of the adsorbate is the vapour phase causes a shift of equilibrium in the direction of desorption. The desorption of chloro-organics proceeds to the vapour phase and out washing by the steam jet. The consecutive stages of out washing and desorption proceed up to the moment of the removal of adsorbate from the adsorbent surface. For $\mathrm{T}>140{ }^{\circ} \mathrm{C}$ the equilibrium is completely shifted to desorption and only out washing of adsorbate from the bed occurs.

Temperature of adsorbent bed is critical in steam regeneration. Upon contact with a cold bed, the inlet steam immediately condenses and the system pressure drops, however after some time the desired conditions roll $\mathrm{back}^{24}$, during this process the heat of condensation leads to rapid but brief heating. Sometimes bed is preheated to avoid condensation. Cabal et al. ${ }^{6}$ found that time of steam regeneration need to be optimized as prolonged time of regeneration cause over reactivation and leads to gasification of adsorbent and damages porous networks of adsorbents. They also found that the steam doesn't modify the basic nature of adsorbent and attributed the change in $\mathrm{pH}$ PZC of regenerated adsorbent to the non-desorbed adsorbate.

Time of regeneration is an important design parameter ${ }^{25}$ and also directly linked to energy consumption and thus cost of regeneration. Regeneration is expected to be complete when effluent gas temperature reaches to regeneration temperature ${ }^{26}$, however this is not applicable to adiabatic systems. Regeneration time is also defined as time at which effluent gas concentration reaches $1 \%$ of feed gas concentration ${ }^{25,27}$. Urano et al. ${ }^{28}$ reported following five elementary processes taking place during steam regeneration of spent granulated activated carbon (GAC) from waste water treatment plant. 
(i) Thermal decomposition of activated carbon, (ii) oxidizing decomposition of activated carbon with steam, (iii) vaporization or sublimation of adsorbate, (iv) thermal decomposition and carbonization of adsorbate, and (v) oxidizing decomposition of carbonized matter with steam.

Different type of adsorbents responds differently to the steam regeneration depending upon their composition and manufacturing e.g., ACF bed was shown to have faster regeneration with steam then GAC bed ${ }^{29}$.

In steam regeneration additional adsorbate is introduced to system as water, which is not desired in both phases and must be removed from adsorber for re-adsorption step ${ }^{20}$. Hence arises need of energy intensive drying step. Despite of this complexity steam is the classical regeneration process in case of activated carbons ${ }^{30}$.

Steam regeneration can be high temperature or low temperature. High temperature steam regeneration is carried in inert environment in order to prevent oxidative reaction of steam with adsorbent and adsorbate which may also cause char formation and result in deterioration of porous network of adsorbent. For the same reason low temperature steam regeneration can be carried in air flow which is cheaper than inert flow. During the heating stage, the carbon passes through the following steps: drying (evaporation of water), thermal desorption (desorption of volatile compounds, 100-260 ${ }^{\circ} \mathrm{C}$ ), pyrolysis and carbonization (pyrolysis and carbonization of non-volatile compounds, 200-650 ${ }^{\circ} \mathrm{C}$ ) and gasification of pyrolytic residue at high temperature $\left(650-850{ }^{\circ} \mathrm{C}\right)$ in the presence of limited amounts of oxidant such as water vapour, oxygen, etc $^{31}$. The selection of steam temperature depends upon the heat capacity of the adsorbent and and the boiling point of organic adsorbate and solvency of inorganic adsorbate. For organic compounds temperature of steam is generally taken $30-50{ }^{\circ} \mathrm{C}$ above the boiling point of adsorbate ${ }^{32}$.

\section{Reaction of steam with adsorbent}

Kuhel \& Timken ${ }^{33}$ found that steaming of zeolite beta at $538{ }^{\circ} \mathrm{C}$ for 10 hours reduced the Bronsted acid site concentration by $75 \%$. Intense steaming of zeolites cause clefts in its crystalline structure, enhances mesoporosity and increases surface area from $1-3 \mathrm{~m}^{2} / \mathrm{g}$, leaving more freshly created Lewis sites accessible, while at same time leads to small decrease or no change in BET micropores surface area and micropore volume ${ }^{34}$. Dealumination has been linked to the increase of affinity of zeolites to saccharides ${ }^{35}$. For zeolites the reaction is shown in Figure 4.

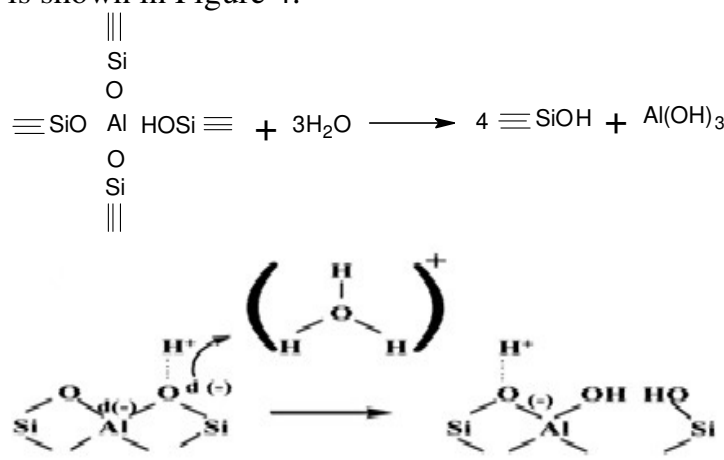

Figure 4. De-alumination of zeolites facilitated by $\operatorname{steam}^{37}$.

For the carbon steam system the principal reactions taking place are given below ${ }^{36}$.

$$
\mathrm{C}+\mathrm{H}_{2} \mathrm{O} \rightarrow \mathrm{CO}+\mathrm{H}_{2} \quad \Delta \mathrm{H}=31.14 \mathrm{kcal}
$$




$$
\begin{array}{cc}
\mathrm{CO}+\mathrm{H}_{2} \mathrm{O} \rightarrow \mathrm{CO}_{2}+\mathrm{H}_{2} & \Delta \mathrm{H}=-9.65 \mathrm{kcal} \\
\mathrm{C}+\mathrm{CO}_{2} \rightarrow 2 \mathrm{CO} & \Delta \mathrm{H}=40.79 \mathrm{kcal} \\
\mathrm{C}+2 \mathrm{H}_{2} \rightarrow \mathrm{CH}_{4} & \Delta \mathrm{H}=-17.87 \mathrm{kcal}
\end{array}
$$

The process of steam regeneration can be divided into following three steps

1. Desorption

2. Drying

3. Cooling

Desorption is carried by steam at desired temperature depending upon solubility of inorganic adsorbate or boiling point of organic compound. If the boiling point of the compound is less than $200{ }^{\circ} \mathrm{C}$ effective regeneration can be achieved using steam ${ }^{14}$. Once temperature for regeneration is fixed, the combination of temperature and pressure is selected using phase diagram of water (Figure 5).

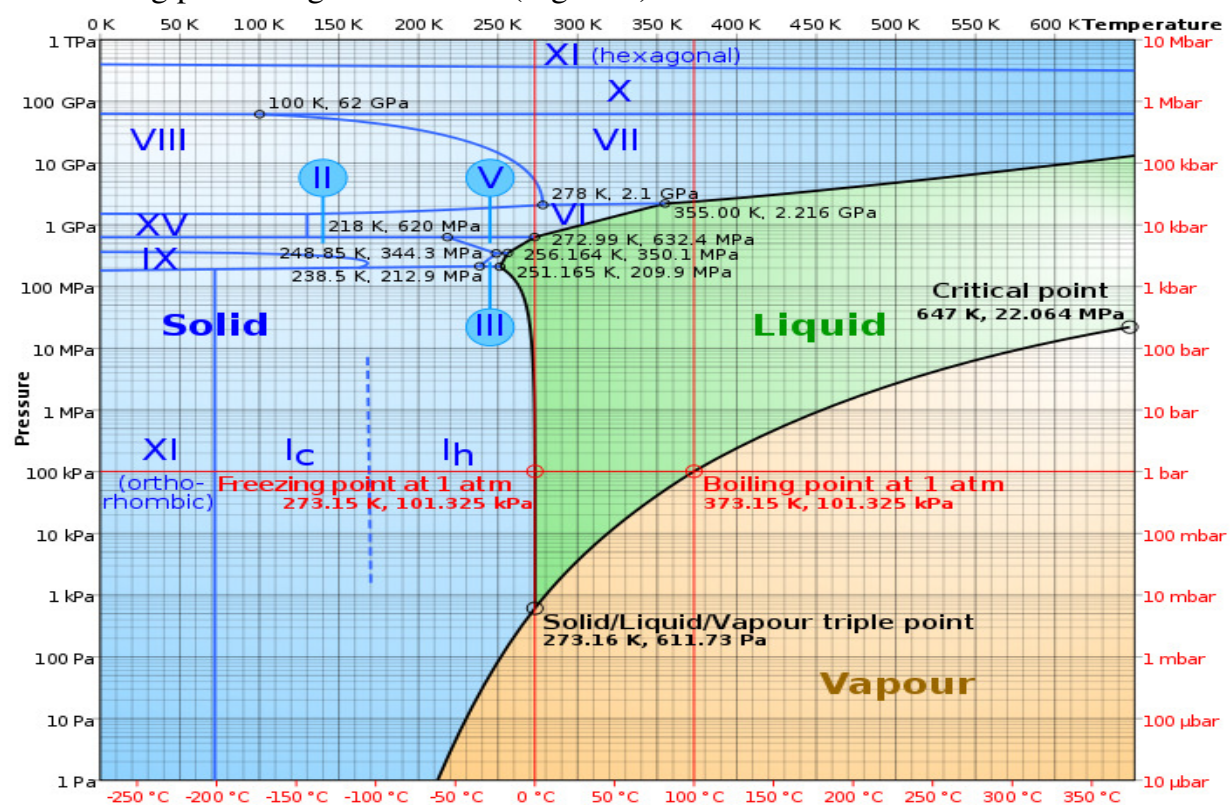

Figure 5. Pressure-temperature phase diagram of water. The Roman numerals indicate various ice phases (Source Wikipedia ${ }^{38}$ )

$\mathrm{Gu} \& \mathrm{Bart}^{18}$ accounted desorption of toluene to heat and mass transfer properties of steam. The criteria selected for the mass flow rate of steam is the bed pressure drop and is generally kept same as during adsorption $\mathrm{step}^{20}$, however maintaining a minimum flow rate is essential to reduce partial pressure of adsorbates in vapour phase and transfer solvent out of bed $^{18}$.The amount of steam required for regeneration will depend on interaction between solvent and activated carbon ${ }^{18}$. Kuntzel et al. ${ }^{20}$ on comparison of two different steam flow rates concluded that to achieve same degree of regeneration same amount of steam will be utilized and for high steam flow rate regeneration time will be less and for low steam flow rate time of regeneration will be more. Steam consumption during desorption step can be quantified either as

- Grams of steam used per gram of adsorbate desorbed.

- Grams of steam used per gram of adsorbent regenerated.

- Number of bed volumes of steam consumed to regenerate single bed of spent adsorbent. 
Generally consumption of steam would be $3-5 \mathrm{~kg}$ of steam per $\mathrm{kg}$ of organic compound desorbed $^{32}$. Drying of bed is important as moisture left un-removed in bed can drastically affect the adsorption capacity and other operational performances ${ }^{39,18}$. Drying ensure that leftover removable moisture as well as adsorbate is removed in order to bring bed back to identical defined starting condition as much as possible ${ }^{20}$. Drying can be fast with heating ${ }^{40}$ or slow without heating ${ }^{41}$. Drying is also fast at the beginning, when the bed is still warm, and it is slow after the bed has cooled to ambient temperature ${ }^{40}$. Drying is most time and energy consuming step in steam regeneration. Drying phase should be designed considering time and cost. In fact in the real situations in industry where steam is mostly available drying is only step in steam regeneration where cost implication is very high. Drying gas used is generally air ${ }^{40}$ or inert gas like nitrogen.

\section{System configuration for steam regeneration}

The system configuration for steam regeneration must include a boiler, a feed water supply and treatment system, provisions for disposing of boiler blow down, a condenser, a separator and adsorbate recovery storage tank. Vapour phase units require a source of drying air also. A separator is not usually required for gas systems because the condensate is a single organic phase. In addition, the carbon adsorbers must be plumbed for steam. The piping to transfer the stripped contaminants to the condenser should be corrosion resistant as desorbate steam mixture can be highly corrosive. A fan or pump for the cooling fluid will be needed if the units must be cooled down faster than radiation will permit. Because adsorption vessels and the spent carbon storage vessel will be heated in steam regeneration, the containers must be designed, fabricated, tested and marked (or stamped) in accordance with the standards codes e.g. Boiler and Pressure Vessel Code ${ }^{42}$ and must incorporate pressure safeguards, such as rupture disks. Wet activated carbon is corrosive, and thus the vessel may be built with a corrosion allowance, typically 0.05 inches. Most are protected with sprayed on linings, which range from 10 to 45 mils thick. A common coating used in carbon adsorption or storage vessels is 30 mils of vinyl chloride. All process leads and lines carrying steam should be insulated by heating tapes ${ }^{43,11}$ in order to prevent condensation

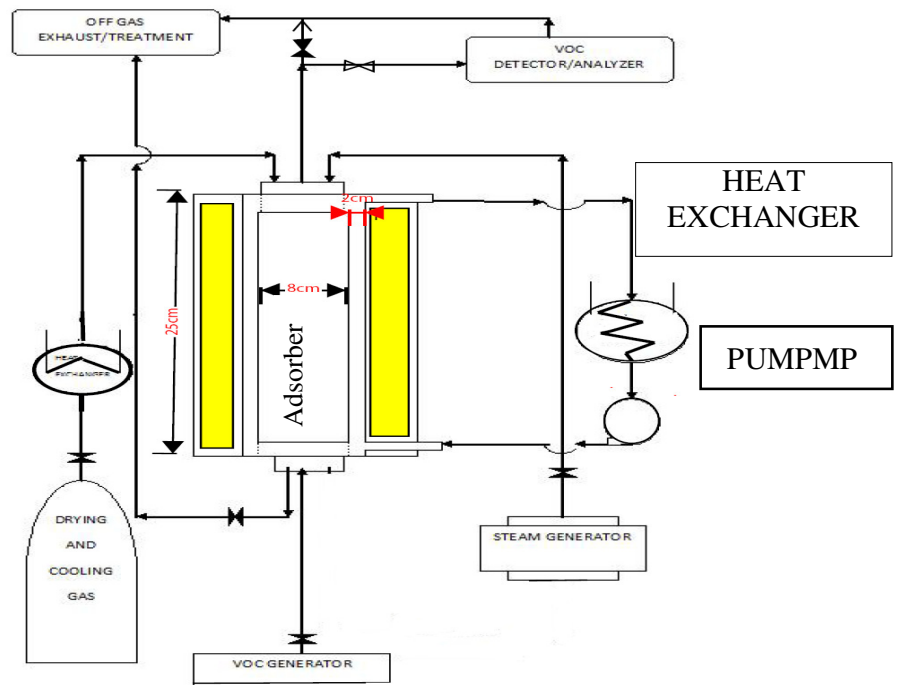

Figure 6. Schematic diagram of typical experimental set up for steam regeneration of VOC spent adsorbents 
The column used in the study of steam regeneration is generally made of steel ${ }^{29}$.Use of materials like glass, Teflon and stainless steel minimizes loss of adsorbate due to adsorption onto process setup ${ }^{11}$. The length of Column is kept possibly less in order to avoid steam condensation $^{29}$. Both ends of Column are packed with materials like glass wool to prevent carryover of adsorbents and end effect ${ }^{29}$. Flow of steam is preferred to be in downward direction as condensed steam could be removed partly by gravity. Drying gas flow is also preferred to be in downward direction, In order to allow evaporation of condensed molecules at bottom to pass minimum distance to outlet.

\section{Estimation of cost of steam production for regeneration}

The quantity of steam required will depend on the amount of carbon in the reactor vessel, the reactor dimensions, the type and amount of adsorbate adsorbed and also on adsorbentadsorbate interactions ${ }^{18}$.

From literature the steam requirement for regeneration process ranges from approximately 3 to $5 \mathrm{~kg}$ of steam $/ \mathrm{kg}$ of adsorbed organic compound ${ }^{32}$. EPA ${ }^{44}$ derived the following equation for determination of annual cost of steam

$$
\mathrm{C}_{\mathrm{s}}=3.5 \times 10^{-3} \cdot \mathrm{M}_{v o c} \cdot \mathrm{T}_{o} \cdot \mathrm{P}_{s}
$$

Where, $\mathrm{C}_{\mathrm{s}}=$ steam cost $(\$ / \mathrm{yr}), \mathrm{T}_{o}=$ system operating hours $(\mathrm{h} / \mathrm{yr}), \mathrm{M}_{v o c}=$ VOC inlet loading $(\mathrm{kg} / \mathrm{h}), \mathrm{P} s=$ Current steam price $(\$ /$ thousand $\mathrm{kg})$.

Where, current steam price $\left(\mathrm{P}_{\mathrm{s}}\right)$ is taken as $120 \%$ of current fuel price. Cost of steam also varies with adsorbate type, loading concentration and flow rates.

\section{Conclusion}

Adsorption is very important unit process for pollution abatement. Efficiency of adsorption process, its diverse applicability and its operator friendliness make it more favourite process in industry for compliance and recovery purpose. However disposal of spent adsorbents is still a topic of debate. With strict legislation surfacing for treatment and storage of spent adsorbent many industries would like to shift to regeneration. The review presented various technical aspects of steam regeneration of adsorbents. Owing to availability and familiarity of steam in industry, it is highly beneficial to utilise steam for regeneration. However drying steamed bed is energy intensive process and more research is required so as to minimize steam consumption and drying time during regeneration cycle. Moreover steam adsorbate reactivity need to be studied, ensuring thermal stability of the material during regeneration.

\section{References}

1. GIA, Global industry analyst incorporation report on Activated Carbon, 2011.

2. Bansal R C and Goyal M, Activated Carbon Adsorption, Boca Raton, FL: Taylor \& Francis., 2005.

3. Tsai W, J Loss Prevent Proc Ind., 2002, 15(2), 147-157.

4. Haderlein S B, Weissmahr K W and Schwarzenbath R P, Environ Sci Technol., 1996, 30(2), 612-622.

5. EPA, OAQPS Control Cost Manual, Office of Air Quality Planning and Standards, Emissions Standards Division, 1996.

6. Cabal B, Tsyntsarski B, Budinova T, Petrov N, Parra J B and Ania C O, J Hazard Mater., 2009, 166(2-3), 1289-1295.

7. Shah I K, Pre P and Alappat B.J, Regeneration of adsorbents spent with Volatile Organic Compounds (VOCs), In Proceedings of International Conference on Environment and Industrial Innovation, Kualalumpur, 2011. 
8. Pelech R, Milchert, E and Wróblewska A, J Colloid Interface Sci., 2005,285(2), 518-524.

9. Brady R D, Activated carbon processes, In Water treatment Plant Design, New York, NY, AWWA, ASCE, McGraw Hill, 2005, pp. 14.1-14.38.

10. Schuliger W G, Riley G N and Wagner N J, Thermal reactivation of GAC: A proven technology. Waterworld News, 1988, 4(1).

11. Suri R P, Crittenden J C and Hand D W, J Environ Engg., 1999, 125(10), 897-905.

12. Pontius, F W, Water quality and treatment, A handbook of community water supplies, New York, NY: McGraw-Hill, 1990.

13. Faust S D and Aly O M, Adsorption Processes for Water Treatment, Boston: Butterworth Publishers, 1987.

14. McKay G, Regeneration of adsorbents In Use of Adsorbents for the Removal of Pollutants from Wastewaters, Boca Raton, FL, CRC Press, 1996.

15. Schweiger A T J, Ind Eng Chem Res., 1995, 34(1), 283-287.

16. Alley R E, Water Quality Control Handbook, $2^{\text {nd }}$ Ed., New York, NY: McGraw-Hill, Inc, 2007.

17. Parmele C S, O'Connell W L and Basdekis H S, Vapor-phase Adsorption Cuts Pollution, Recovers Solvents, Chemical Engineering, 31 December 1979, 58-70.

18. Gu J and Bart H J, Int Commun Heat Mass Transf., 2005, 32(3-4), 296-304.

19. Schweiger T A J, Experimental and Theoretical Studies of Steam Regeneration of a Solvent Adsorber, Charlottesville, VA (US); Univ of Virginia, 1989.

20. Küntzel J, Ham R and Melin T, Chem Eng Technol., 1999, 22(12), 991-994.

21. Scamehorn J F, Ind Eng Chem Process Des Dev., 1979, 18(2), 210-217.

22. Schork J M and Fair J R, Ind Eng Chem Res., 1988a, 27(3), 457-469.

23. George C E, Azwell D E, Adams P A, Daniel E Averett and Rao G V N, Waste Management, 1995, 15(5-6), 407-416.

24. Schork J M and Fair J R, Ind Eng Chem Res., 1988b, 27(8), 1545-1547.

25. Hwang K S, Choi D K, Gong, S Y and Cho S Y, Chem Eng Sci., 1997, 52(7), 1111-1123.

26. Kumar R and Dissinger G R, Ind Eng Chem Process Des Dev., 1986, 25(2), 456-464.

27. Huang C C and Fair J R, A I Ch E J, 1988, 34(11), 1861-1877

28. Urano K, Yamamoto E and Takeda H, Ind Eng Chem Proc Des Dev., 1982, 21(1), 180-185.

29. Kim J-H, Ryu Y-K, Haam S, Lee C-H and Kim W-S, Separ Sci Technol, 2001, 36(2), 263-281.

30. Kast W, Adsorption aus der Gasphase, Weinheim: VCH Verlagsgesellschaft mbH, 1988.

31. Salvador S and Jimenez C S, Carbon, 1996, 34(4), 511-516.

32. Woods D R, Rules of thumb in Engineering practices, Weinheim: Wiley Verlag Publications, 2007, 118-119.

33. Kuehl G H and Timken H K C, Microporous and Mesoporous Mat., 2000, 35-36, 521-532.

34. Van Bokhoven J A, Koningsberger D C, Kunkeler P and van Bekkum H, J Catal., 2002, 211(2), 540-547.

35. Buttersack C, Wach W and Buchholz K, J Phys Chem., 1993, 97(46), 11861-11864,

36. Kiel H E, Sahaglan J and Sundstrom D W, Ind Eng Chem Proc Des Dev., 1975, 14(4), 470-473.

37. Trujillo C A, Uribe U N, Knops-Gerrits P-P, Oviedo L A A and Jacobs P A, J Catal., 1997, 168(1), 1-15.

38. Encyclopedia, Phase diagram, Wikimedia Foundation, Inc,: http://En.wikipedia.org/wiki/Phase_diagram

39. Mastroianni M L and Rochelle S G, Environ Prog., 1985, 4(1), 7-14. 
40. Gu J, Faquir N M and Bart H-J, Chem Eng Technol., 1999, 22(10), 859-864.

41. Scamehorn J F, Ind Eng Chem Process Des Dev., 1979, 18(2), 210-217.

42. ASME, Boiler and Pressure Vessel Code, American Society of Mechanical Engineers, New York, NY, 1992.

43. She H Y and Sleep B E, Ground Water Monit Rem., 1999, 19(2), 70-77.

44. EPA, Process Design Manual for Carbon Adsorption, US Environmental Protection Agency, 1973. 